http://dx.doi.org/10.5209/FORO.57533

\title{
SOBRE LA DEMOCRACIA PARITARIA
}

\author{
Ignacio Álvarez RoDRígueZ \\ Investigador del Instituto \\ de Derecho Parlamentario \\ Universidad Complutense de Madrid. \\ Congreso de los Diputados \\ ignacioalvrod@gmail.com
}

\section{INTRODUCCIÓN}

El objetivo de las siguientes líneas es exponer la evolución que ha experimentado la teoría de la democracia paritaria. Para ello se aborda en primer lugar la democracia paritaria 1.0, apartado que repasa sus orígenes, concepto, caracteres y los factores que influyen en su consecución. En segundo lugar se expone la democracia paritaria 2.0, donde se reformulan elementos de la anterior y se añaden algunos nuevos. Finalizan unas conclusiones a modo de colofón, que sometemos a la mejor opinión de la doctrina.

\section{LA DEMOCRACIA PARITARIA 1.0}

La democracia paritaria se recoge por primera vez en la Declaración de Atenas de $1992^{1}$. A invitación de la Comisión de las Comunidades Europeas se creó la primera Cumbre Europea Mujeres al poder, celebrada en la ciudad griega. En ella se plasmaron las bases que posteriormente han sido desarrolladas a lo largo y ancho del mundo. Desde sus comienzos no deja lugar a dudas, uniendo inexorablemente democracia y paridad (la mujer constituye la mitad de las inteligencias y de las capacidades), y proclamando, en consecuencia, la necesidad de alcanzar un reparto equilibrado del poder político.

1 Vid. J. Sevilla Merino, Mujeres y ciudadanía: la democracia paritaria, Valencia, Institut Universitari d'Estudis de la Dona-Universitat de València, 2004, p. 27; E. Martínez SEMPERE, «La legitimidad de la democracia paritaria», Revista de Estudios Políticos, núm. 107 (2000), p. 133, y M. BoIX, «La representación de las mujeres y la lucha por la paridad: aproximación histórica», El Periódico Feminista en Red, disponible en http://www.nodo50. org/mujeresred/spip.php?article273 (consultado el 24 de junio de 2017). 
La cobertura jurídica internacional ha llegado desde tres instituciones. En primer lugar, de Naciones Unidas, mediante el art. 7 CEDAW de 1981, en el que se requiere a los Estados que tomen aquellas medidas necesarias para eliminar la discriminación contra la mujer en la vida política y pública del país, garantizando en particular el derecho a votar y ser votadas (en sentido amplio). A nivel institucional, la apuesta decidida y firme por la democracia paritaria se plasma en la Declaración de Beijing, redactada con motivo de la IV Conferencia sobre la Mujer de 1995. De ese modo, el punto 13 de la misma considera que el empoderamiento de las mujeres y su plena participación en todas las esferas de la sociedad son fundamentales para el logro de la igualdad, el desarrollo y la paz. Tanto el informe de la 49. ${ }^{a}$ sesión de la Comisión Jurídica y Social de la Mujer de la ONU como el informe redactado con motivo de la 50.a sesión (en 2005 y 2006, respectivamente) sustentan y animan a conseguir tal objetivo en el marco de la plataforma de acción constituida a efectos de igualdad entre mujeres y hombres².

En segundo lugar, del Consejo de Europa, sobre todo con la prohibición de discriminación de toda persona bajo la jurisdicción de cualquier Estado miembro, rubricado en el art. $14 \mathrm{CEDH}$ y en el Protocolo núm. 1233. Ya en 1989 el Consejo organizó una conferencia/seminario para tratar el asunto de la igual representación en política de ambos sexos ${ }^{4}$; por otro lado, se creó en su momento un grupo de expertos cuyo cometido era elaborar, analizar y estudiar las posibilidades de dicho modelo de democracia. Debe tenerse en cuenta, adicionalmente, la Recomendación 1413 (1999) de la Asamblea Parlamentaria, en la que se invita a las delegaciones nacionales a que promuevan en sus Parlamentos la introducción de medi-

${ }^{2}$ El Consejo Interparlamentario de la UNESCO en su 161. a sesión, celebrada en El Cairo en 1997, adoptó la Declaración Universal sobre la Democracia, en la que defiende la paridad, considerando la democracia como «una auténtica asociación entre hombres y mujeres para la buena marcha de los asuntos públicos, de modo que tanto los hombres como las mujeres actúen en igualdad y complementariedad». Disponible en bttp://www.UNESCO. $\mathrm{org} / \mathrm{cpp} / \mathrm{sp} /$ declaraciones/democracia.btm (consultado el 24 de junio de 2017).

3 Vid. E. Carmona Cuenca, «La prohibición de discriminación: nuevos contenidos (art. 14 CEDH y Protocolo 12)», en J. García Roca y P. Santolaya Machetti (coords.), La Europa de los derechos: el Convenio Europeo de Derechos Humanos, 3. ${ }^{a}$ ed., Madrid, CEPC, 2014, pp. 733-764; vid. también E. Carmona Cuenca, M. Arenas Ramiro, Y. FernándeZ Vivas y F. Plovesán, «Los derechos humanos con perspectiva de género», en J. García Roca y E. Carmona Cuenca (coords.), ¿Hacia una globalización de los derechos? El impacto de las sentencias del Tribunal Europeo y de la Corte Interamericana, Pamplona, Thomson Reuters-Aranzadi, 2017, pp. 315-362.

${ }^{4}$ Vid. M. SubIRATS MARTORI, «Democracia paritaria: recorrido histórico y planteamiento actual», en P. SAAVEDRA (dir.), Hacia la democracia paritaria. Análisis y revisión de las leyes electorales vigentes, Madrid, CELEM, 1999, p. 44. 
das específicas para corregir la escasa representación de la mujer en la vida política, intentando alcanzar la representación equilibrada en las Cámaras. El aldabonazo definitivo viene con la Recomendación 3 (2003), sobre participación equilibrada de las mujeres y los hombres en los procesos de toma de decisión en los ámbitos político y público, plasmando una amplia batería de medidas con las que hacer efectivo el principio paritario, incluso con cambios constitucionales, llegado el caso.

En tercer lugar, la Unión Europea ${ }^{5}$. Así, la Recomendación del Consejo de 2 de diciembre de 1996 — relativa a la participación equilibrada de mujeres y hombres en los procesos de toma de decisión- se dirige a los Estados miembros con objeto de que adopten aquellas disposiciones necesarias para que hombres y mujeres participen equilibradamente en las instancias de poder, desarrollando las pertinentes medidas incentivadoras y/o legales a tal fin. La Resolución del Parlamento Europeo núm. 169 (1998) aboga porque los partidos políticos adopten un sistema de cuotas con objeto de alcanzar la igualdad numérica de género en los órganos de representación política. En la misma línea actúan las Resoluciones de 3 de marzo de 2000, de 5 de julio de 2001 y de 2 de febrero de 2006, todas ellas del Parlamento.

Institucionalmente, y recuperando el espíritu del documento de 1992, la UE ha promovido e impulsado la celebración de cumbres similares que, sin excepción, han concluido con sendas declaraciones en las que destacan dos cuestiones. La primera es la constante infrarrepresentación de la mujer en las instituciones; la segunda es el posible remedio a dicho mal: la democracia paritaria. Prueba de ello es la Carta de Roma de 18 de mayo de 1996, redactada al finalizar la Cumbre Europea Las mujeres por la renovación de la política y de la sociedad, y la Declaración de París de 17 de abril de 1999, documento de consenso que vio la luz al finalizar la Cumbre Europea Mujeres y hombres al poder.

\section{CONCEPTO}

Dentro del concepto podríamos destacar un concepto etimológico y un concepto doctrinal.

5 Vid. J. Sevilla Merino, «Democracia paritaria y Unión Europea», en M. E. PasTOR GosálBEZ (coord.), Integración europea y género, Madrid, Tecnos, 2014, pp. 155-177, y T. Freixés Sanjuan, «Fundamentos de la democracia paritaria: el Tratado de Ámsterdam y los acuerdos internacionales», en P. SAAVEDRA (dir.), La democracia paritaria en la construcción europea, Madrid, CELEM, 2000, pp. 87-96. 
Etimológicamente, paridad significa igualdad de las cosas entre sí. Una democracia paritaria sería una democracia de iguales, un sistema de iguales. Dicho de una comisión o de una asamblea: «que las diversas partes que la forman tienen igualdad en el número y derechos de sus miembros» ${ }^{6}$.

Doctrinalmente, las ideas discurren por similar camino. De ello tenemos ejemplos longevos y novedosos. Dentro de los primeros, algunos cifran la democracia paritaria en la representación equilibrada de ambos sexos en las funciones decisorias (entre el 40 y el 60 por 100). Sería un principio estructural de la democracia ${ }^{7}$. De acuerdo con Le Doaré, con la democracia paritaria se debe contribuir a refundar un sistema democrático que actualmente es todavía manifiestamente deficiente «ya que no ha podido integrar a la mitad de los ciudadanos» ${ }^{8}$. Martínez Sempere defiende un concepto amplio e integrador, sinónimo de un reparto del poder entre los hombres y las mujeres que requiere una nueva definición de la democracia. La idea que prima por encima de todas es la distribución equitativa del poder político entre los dos sexos, planteamiento que la propia autora reconocer tributario de Agacinski ${ }^{9}$. De parecidas influencias se nutre Guerra al exponer que la democracia paritaria es un factor de mejora de los actuales modelos de democracia representativa. Supone dejar atrás, como una fase en el camino, la estrategia de las cuotas femeninas y dar un paso definitivo en la esfera política ${ }^{10}$. Para Macías Jara, la democracia paritaria sería aquella democracia que incluye la representación suficiente de hombres y de mujeres en el poder y en la toma de decisiones. Defiende luego que es, pues, un principio básico, un postulado que ha de inspirar y fundamentar la actuación de los poderes públicos y, en general, todo el entramado jurídico y político para la consecución de la igualdad de género. Por ello, también constituye una garantía para la salvaguarda de la igualdad en la realización de los dere-

${ }^{6} \mathrm{Vid}$. bttp://buscon.rae.es/draeI/SrvltConsulta?TIPO_BUS=3ELEMA=paritaria (consultado el 25 de junio de 2017).

7 Vid. voz «Democracia paritaria», en 100 palabras para la igualdad. Glosario de términos relativos a la igualdad entre hombres y mujeres, Comisión Europea, Dirección General de Empleo, Relaciones Laborales y Asuntos Sociales, 1998, disponible en bttp://www. europarl.europa.eu/transl_es/plataforma/pagina/celter/glosario_genero.btm\#D (consultado el 25 de junio de 2017).

${ }^{8}$ H. le Doaré, voz «Paridad», en H. Hirata, F. Laborie, H. le Doaré y D. Senotier (coords.), Diccionario crítico del feminismo, Madrid, Síntesis, 2002, p. 179.

9 Vid. S. Agacinski, Política de sexos, Madrid, Taurus, 1998, y E. Martínez Sempere, «La legitimidad de la democracia...», op. cit., pp. 140 y ss.

${ }_{10} \mathrm{M}^{a}{ }^{a} \mathrm{~J}$. GUERRA, «Democracia paritaria e inclusión: reflexiones feministas», en A. SIERRA GonzÁlez y M. ${ }^{a}$ P. DE la Nuez Ruiz (eds.), Democracia paritaria (aportaciones para un debate), Barcelona, Laertes, 2007, p. 75. 
chos sociales y políticos de las mujeres - y de los hombres-, incluyendo el derecho al sufragio pasivo. Y concluye aclarando que hablar en términos de democracia paritaria no significa más que entender que, en democracia, las mujeres y los hombres han de formar parte de las elites políticas para que la defensa de sus intereses y de sus derechos no quede en manos ajenas ${ }^{11}$. Gallego Méndez, haciéndose eco de la Declaración de Atenas, defiende que hablar de democracia paritaria es hablar de total integración, en pie de igualdad, de las mujeres en las sociedades democráticas, utilizando para ello las estrategias multidisciplinares que sean necesarias ${ }^{12}$.

Dentro de los más novedosos destaca la de Aldeguer Cerdá, para quien la democracia paritaria es la presencia equilibrada de las mujeres (en las instituciones públicas) en el seno de los umbrales comprendidos entre el 40 y el 60 por $100^{13}$; opinión que en términos muy similares enuncian Vergé ${ }^{14}$ y Jenson y Valiente ${ }^{15}$, entre otras.

\section{CARACTERES}

Cabe destacar dos grandes tipos de caracteres. Por un lado, los caracteres teóricos y, por otro, los caracteres prácticos.

\section{Los caracteres teóricos}

El primer sustrato teórico lo encontramos en la crítica al patriarcado, crítica que se hace sobre todo contra su acto fundacional: el contrato

${ }^{11}$ M. MACÍAS JARA, «La democracia representativa paritaria. Algunas cuestiones en torno a la LO 3/2007, de 22 de marzo, para la igualdad efectiva de mujeres y hombres», Aequalitas, núm. 23 (2008), pp. 23 y 24, e íD., «Democracia representativa paritaria y ciudadanía», en M. ${ }^{a}$ S. DE LA Fuente NúÑEZ de Castro y A. Liñán García (coords.), Género y Derecho. Luces y sombras en el ordenamiento jurídico español, Málaga, Centro de Ediciones de la Diputación de Málaga, 2008, pp. 178 y ss.

${ }_{12} \mathrm{M}^{a}{ }^{a}$ T. Gallego MÉNDEZ, «Democracia paritaria: recorrido histórico y planteamiento actual», en P. SAAVEDRA (dir.), Hacia la democracia paritaria. Análisis y revisión de las leyes electorales vigentes, Madrid, CELEM, 1999, p. 53.

13 Vid. B. Aldeguer CeRdÁ, Democracia paritaria y cuotas electorales. El acceso de las mujeres a las instituciones públicas, Valencia, Tirant lo Blanch-Universidad de Alicante, 2016, p. 22.

14 T. Verge, «De la cuota a la democracia paritaria: estrategias partidistas y representación política de las mujeres en España», Política. Revista de Ciencia Política, núm. 46 (2006), pp. 107-139.

${ }_{15}$ C. Valiente y J. Jenson, «El movimiento a favor de la democracia paritaria en Francia y España», Revista Española de Ciencia Política, núm. 5 (2001), pp. 79-110. 
social en general y la idea de Rousseau en particular ${ }^{16}$. El contrato social no es sino el comienzo de la era patriarcal — dirá Carole Pateman—, puesto que lo que encierra es otro sexual: son únicamente los hombres los que toman las riendas de la sociedad política, los que la constituyen y gobiernan. El otro sexo, la mujer, no queda incluida en el pacto ${ }^{17}$. Para dejar escaso margen a la duda, el propio Rousseau expuso en 1762 el papel que la mujer debía tener en el entramado político-social: mientras que Emilio (prototipo de hombre roussoniano) se encarga de todo aquello relacionado con la esfera pública, Sofía debe ocuparse de los asuntos doméstico-privados, amén de complacerle en lo que fuere necesario. La base en la que se cimentó el modelo previamente había atribuido ciertas características naturales a cada sexo que, automáticamente, se hicieron pasar por sociales, perpetuándose a lo largo y ancho de los siguientes siglos. De muestra un botón: dirá Rousseau que «en la unión de sexos cada uno concurre por igual al objeto común, pero no de un mismo modo. De esta diversidad nace la primera diferencia notable entre las relaciones morales de uno y otro. El uno debe ser activo y fuerte, débil y pasivo el otro. Asentado este principio, se sigue que el destino especial de la mujer es agradar al hombre. Si recíprocamente debe agradarle el hombre a ella, es una necesidad menos directa: el mérito del varón consiste en un poder, y sólo por ser fuerte agrada. Ésta no sería la ley del amor, pero sí la ley de la Naturaleza, más antigua que el amor mismo» ${ }^{18}$. No puede olvidarse que ya en 1791 este esquema fue criticado duramente por una de las precursoras del feminismo, Olimpia de Gouges, cuando redacta la Declaración de Derechos de la Mujer y de la Ciudadana (como reacción ante la ausencia de aquélla de la Declaración francesa de 1789). La mujer siempre estuvo ahí. La idea, también.

El segundo carácter teórico viene de la dialéctica entre el feminismo de la igualdad y entronca con el feminismo de la diferencia; es decir, de lo que resulte de confrontar los dos modelos ${ }^{19}$.

16 J. J. Rousseau, Del contrato social. Sobre las ciencias y las artes. Sobre el origen y los fundamentos de la desigualdad entre los hombres, Madrid, Alianza, 2005, pp. 21-166. Sobre el contrato social aporta ideas muy sugerentes J. L. PARDO, Estudios del malestar. Políticas de la autenticidad en las sociedades contemporáneas, Barcelona, Anagrama, 2016, pp. 145 y ss.

17 C. Pateman, El contrato sexual, Barcelona, Anthropos, 1995, p. 9.

18 J. J. Rousseau, Emilio o De la educación, México, Porrúa, 1970, pp. 278 y 279.

19 Dicha respuesta no puede darse sin dejar de reconocer que las líneas trazadas entre uno y otro sistema no son tan nítidas como podría parecer. Esto creemos que ocurre con los modelos explicitados por Luigi Ferrajoli. A grandes rasgos, el constitucionalista italiano pro- 
Históricamente, el feminismo nace como feminismo de la igualdad, íntimamente ligado a la Ilustración. Su posicionamiento de principio es que los valores ilustrados se hagan realidad también para la porción femenina de la humanidad que ha sido dejada de lado. En definitiva, y tal como ha expuesto Amelia Valcárcel, el feminismo vendría a ser un hijo no querido de la Ilustración ${ }^{20}$. Nos encontramos ante la reivindicación de la igualdad en un contexto liberal que intenta traducir conquistas políticas en graduales reformas legislativas (y viceversa) ${ }^{21}$.

A raíz de los movimientos políticos y sociales ocurridos en torno al mayo del 68 francés, el movimiento feminista sufrió una fuerte sacudida de la que parece siguen resonando sus ecos. Ante las conquistas de derechos por parte de las mujeres, ciertos sectores reaccionan críticamente; a pesar de la plasmación formal de los mismos, la realidad es bien distinta, ya que nada parece haber cambiado, estructuralmente hablando. ¿El motivo? El feminismo liberal sufragista habría incurrido en una visión viciada, puesto que el anhelo de igualarse con los mecanismos, derechos y normas elaboradas por los varones implicaba aceptar tácitamente el esquema patriarcal masculino, perpetuando el mismo y subyugando la condición femenina. La participación en y de las instituciones estableci-

pone hasta cuatro esquemas jurídicos: el primero sería la indiferencia jurídica ante las diferencias; el segundo, la diferenciación jurídica de las diferencias, jerarquizando entre las observadas; el tercero quedaría constituido por la homologación jurídica de aquéllas, mientras que el cuarto sería la valoración jurídica de las mismas. Este último, paradójicamente, se basa a su vez en el principio normativo de igualdad, en los derechos fundamentales - políticos, civiles, de libertad y sociales - y, al mismo tiempo, en un sistema de garantías capaces de asegurar su efectividad. Vid. L. FerRajoli, Derechos y garantías. La ley del más débil, Madrid, Trotta, 2004, en especial su capítulo III, «Igualdad y diferencia», pp. 73-96. Idea también sumamente interesante es la que expone cuando dice que la igualdad como norma proviene, a su vez, de dos extremos que confluyen: de la necesaria tutela de las diferencias, esto es, de las identidades personales de cada cual, valor a proteger, y de las desigualdades que anidan en la sociedad, esto es, las diferentes condiciones materiales de vida que, al ser un desvalor, merecerían ser combatidas (entre otros remedios) a través de acciones positivas. Vid. L. FerRajoli, «La igualdad y sus garantías», en A. Ruiz Miguel y A. Macía MoriLlo (eds.), Desafíos de la igualdad, desafíos a la igualdad, Anuario de la Facultad de Derecho de la Universidad Autónoma de Madrid, núm. 13 (2009), pp. 311-325.

20 A. VAlCÁrCEL, «La memoria colectiva y los retos del feminismo», Naciones Unidas, Serie Mujer y desarrollo, núm. 31 (2001), p. 8. De la misma autora se puede consultar «El derecho al mal» (Apéndice), en Sexo y filosofía. Sobre «mujer» y «poder», Barcelona, Anthropos, 1994, p. 162. Vid. también C. Amorós, «Feminismo e Ilustración», en R. CAPEL (ed.), Historia de una conquista: Clara Campoamor y el voto femenino, Madrid, Dirección General de la Mujer del Ayuntamiento de Madrid, 2007, pp. 34-49.

${ }^{21}$ G. M. SCANLON, «Orígenes y evolución del movimiento feminista contemporáneo», en P. Folguera (ed.), El feminismo en España. Dos siglos de historia, Madrid, Pablo Iglesias, 2007, pp. 219-249. 
das habría conducido, una vez más, a la imposibilidad de realizar el proyecto femenino ${ }^{22}$.

Por lo que se aboga ahora es por tener en cuenta las diferencias. Ser mujer y ser hombre son las únicas dos formas del ser humano (idea de la mixitud propuesta por Sylviane Agacinski) ${ }^{23}$. Partiendo de dicha base, lo que no se debe hacer es eliminar las particularidades femeninas bajo el manto de una supuesta igualdad abstracta y universal (porque la práctica habría demostrado los nefastos efectos de dicha opción), sino que habría que potenciarlas y desarrollarlas en todos los aspectos de la vida, cambiando completamente las estructuras de poder, acudiendo al proceso revolucionario en caso de que fuera necesario. Ante el lugar de lo mismo se reclama el lugar de lo otro, que será definido como aquel espacio reivindicativo de construcción y reconstrucción de una identidad propia ${ }^{24}$. Irigaray sintetiza bien este modo de pensar, sosteniendo que reclamar la igualdad, como mujeres, es la expresión equivocada de un objetivo acertado. Reclamar la igualdad implica un término de comparación. ¿A qué o a quién desean igualarse las mujeres? ¿A los hombres? ¿A un salario? ¿A un puesto público? ¿A qué modelo? ¿Por qué no a sí mismas? Y concluye: si la explotación femenina está basada en la diferencia sexual, sólo a través de la diferencia sexual puede resolverse ${ }^{25}$.

Teniendo en cuenta el modesto repaso realizado del significado básico de las dos principales ramas del feminismo ${ }^{26}$, debemos contestar a la pre-

22 A. Rubio Castro, «El feminismo de la diferencia: los argumentos de una igualdad compleja», Revista de Estudios Políticos, núm. 70 (1990), p. 188.

${ }^{23}$ S. Agacinski, Política de sexos, op. cit.

${ }^{24}$ R. M. ${ }^{a}$ Rodríguez Magda, «El feminismo francés de la diferencia», en C. Amorós (coord.), Historia de la teoría feminista, Madrid, Comunidad de Madrid-Instituto de Investigaciones Feministas, 1994, p 205.

${ }^{25}$ L. Irigaray, Yo, tú, nosotras, Madrid, Ediciones Cátedra-Universitat de Valéncia-Instituto de la Mujer, 1992, p. 9.

${ }^{26}$ No se obvia que dicha filosofía es mucho más rica y prolija que la apuntada por tal divisoria. Existen múltiples corrientes dentro del mismo corpus teórico, tales como el feminismo socialista, el feminismo burgués o el marxista. Para profundizar en tales aspectos se puede consultar C. Amorós (coord.), Historia de la teoría feminista, Madrid, Comunidad de Madrid-Instituto de Investigaciones Feministas, 1994, nota 168, y N. VArela, Feminismo para principiantes, Barcelona, Ediciones B, 2013. Mención aparte merecería el feminismo institucional, cuyo desarrollo tuvo lugar a medida que el feminismo de la diferencia fue perdiendo fuelle a partir del último tercio del siglo Xx. Éste postula que las mujeres gozarían de mayores oportunidades y posibilidades de integrarse en las diferentes esferas sociopolíticas del sistema, no reivindicando desde fuera. El principal ejemplo son los países nórdicos o escandinavos (Suecia, Noruega, Dinamarca, Finlandia e Islandia). Vid. J. Lovenduski, «Feminismo institucional: género y Estado», en E. Uriarte y A. Elizondo (coords.), Mujeres en política, Barcelona, Ariel, 1997, p. 204. Vid. también R. M. ${ }^{a}$ BERENGUER, «Las mujeres 
gunta que queda pendiente: ¿a qué corriente quedaría adscrita la democracia paritaria? Algunas autoras responden que a las $\operatorname{dos}^{27}$. Según esta visión, desde el postulado de la diferencia, la paridad puede ser vista como la realización de esa diferencia esencial y natural entre mujeres y hombres. La controversia se dirimiría así: dado que el género humano es siempre hombre o mujer (y nunca dejará de serlo), todas las facetas de la vida deberían estructurarse conforme a tal criterio. La rama político-representativa de la misma no podría quedar, lógicamente, al margen. Pero a su vez, la democracia paritaria puede fundarse en el planteamiento igualitario, ya que mediante la misma se estaría realizando, justamente, esa universalidad hurtada por el patriarcado, restableciendo la igualdad y la libertad prometida (pero no conseguida). De suyo deriva que la paridad no actuaría como un principio, sino como una estrategia encaminada a ampliar las cotas de libertad, igualdad y autonomía de las mujeres ${ }^{28}$. No obstante, parece que la democracia paritaria suele ser vista con mejor ojos dentro del feminismo ilustrado e igualitario ${ }^{29}$. Algunos autores van más allá, defendiendo que la auténtica democracia paritaria sólo encaja con el feminismo de la igualdad ${ }^{30}$. Ello lo confirma el hecho de que los intentos por alcanzar la democracia paritaria a lo largo y ancho del mundo se están haciendo dentro de las instituciones y no contra ellas (al menos no en sentido revolucionario) ${ }^{31}$.

El tercer carácter es la representación descriptiva, idea muy ligada históricamente al debate de las políticas de la presencia/del reconocimiento ${ }^{32}$.

en la élite parlamentaria y la igualdad», en J. MarTín CuBAs (coord.), Constitución, Política y Administración, Valencia, Tirant lo Blanch, 2017, pp. 297-311.

${ }_{27}$ R. Cово, «Democracia paritaria y sujeto político feminista», Anales de la Cátedra Francisco Suárez, núm. 36 (2002), p. 35, y A. Rubio Castro, «Igualdad y diferencia. ¿Dos principios jurídicos?», Derechos y libertades. Revista del Instituto Bartolomé de las Casas, núm. 4 (1995), p. 279.

${ }_{28}$ R. Cово, «Democracia paritaria...», op. cit., p. 38.

29 En ese sentido, M. ${ }^{a}$ J. PALmero Guerra, Teoría feminista contemporánea. Una aproximación desde la ética, Madrid, Editorial Complutense, 2001, p. 103.

30 E. Aranda Álvarez, Democracia paritaria. Un estudio crítico, Madrid, CEPC, 2013, pp. 60 y ss.

31 Existen, claro está, posturas mucho más radicales que defenderían el cuanto peor, mejor, justamente porque cuanto más medidas se adoptan, más se integra a la mujer en el sistema, más se la iguala con el hombre, más dominada y subyugada permanecería, y mucho más costaría liberarse del yugo patriarcal. Más se la domestica, en suma. Vid. C. GonzáLEZ MARÍN, «La inclusión como impotencia», en L. BRANCIFORTE y R. ORSI (eds.), La guillotina del poder. Género y acción sociopolítica, México, Plaza y Valdés, 2015, pp. 180 y ss., y A. Campos Rubio, «Participación y representación política de las mujeres: el MF y el 100 por 100 de la representación», Revista Vasca de Administración Pública, núm. 99-100 (2014), pp. 745-763.

32 Vid. A. Phillips, The Politics of Presence, London-New York-Oxford, Oxford Uni- 
Partiendo de la base de que las asambleas representativas deben reflejar las sociedades de la forma más fiel posible (como un espejo) ${ }^{33}$, el principal argumento en el que descansa esta concepción es en la existencia de determinados grupos sociales que, siguiendo diferentes características visibles que les son inherentes, merecen ser reconocidos y tratados en función de las mismas. Combatiendo el ideal abstracto de igualdad (que laminaría las mismas), se pretende que las instituciones políticas reposen sobre el principio de realidad más que sobre ese abstracto ciudadano. A mayores, se argumenta que es cuestión de elemental justicia o que así lo exige la defensa de los intereses específicos del grupo en cuestión, por mencionar dos ${ }^{34}$.

Lo importante ahora es romper el techo de cristal mediante la consolidación de una masa crítica ${ }^{35}$. Tal masa se sitúa en torno al 30-40 por 100 de mujeres, exigencia irrenunciable para que se produzcan cambios estructurales y tengan influencia política. Existe una unión, más o menos explícita, aglutinada en torno a la idea de que a mayor representación descriptiva, mayor y mejor representación sustantiva; es decir, a más mujeres, más y mejor defensa de los intereses de las mujeres. Dicho eso así, no puede obviarse que la configuración constitucional encaja mal tales exigencias ${ }^{36}$.

La cuarta característica es la defensa de la democracia participativa. Y es que la democracia paritaria quiere, o necesita, una democracia participativa $^{37}$. Es aceptada la separación entre la democracia de los clásicos (la de

versity Press, 1995; I. M. Young, Inclusion and Democracy, Oxford, Oxford University Press, 2000, e íD., La justicia y la política de la diferencia, Madrid, Ediciones Cátedra, 2000. También puede verse D. InNERARITY, «Políticas del reconocimiento», Hermes. Revista de Pensamiento e Historia, núm. 30 (2009), pp. 4-12, y, con el mismo título, en Claves de Razón Práctica, núm. 194 (2009), pp. 28-33.

33 H. PITKIN, El concepto de representación, Madrid, CEPC, 2014, p. 66.

34 E. GarCía Guitián, «Crisis de la representación política: las exigencias de la política de la presencia», Revista de Estudios Políticos, núm. 111 (2001), pp. 220 y 221, y A. PHILLIPS, «La política de la presencia: la reforma de la representación política», en S. GARCíA y S. Lukes (eds.), Ciudadanía, justicia social y participación, Madrid, Siglo XXI, 1999, p. 248.

35 Vid. D. Dahlerup, «The Story of the Theory of Critical Mass», Politics and Gender, vol. 2, núm. 4 (2006), pp. 511 y ss.

36 Sobre todo por la prohibición del mandato imperativo. Es sabido que no hay representación sin mandato representativo. Vid. G. SARTORI, «En defensa de la representación política», Claves de Razón Práctica, núm. 91 (1999), pp. 3 y 4; C. FernÁNDEz-Miranda CamPOAMOR y A. Fernández-Miranda CAMPOAmor, Sistema electoral, partidos políticos y Parlamento, Madrid, Colex, 2008, pp. 111 y ss; J. J. Linz, «Problemas de la democracia hoy», en J. Montabés Pereira (coord.), El sistema electoral a debate: veinte años de rendimiento del sistema electoral español (1977-1997), Sevilla, CIS-Parlamento de Andalucía, 1998, p. 28; e I. Torres Muro, «El transfuguismo político. Un elogio (moderado) del tránsfuga», Revista de Estudios Jurídicos, núm. 16 (2016), pp. 6 y ss.

${ }^{37} \mathrm{La}$ diferencia de género es uno de los retos transformadores contemporáneos. Vid. 
Pericles, la que se desarrolló en la Grecia del siglo iv a. C.) y la democracia moderna (la de Constant, Sieyés, Montesquieu, Tocqueville y Stuart Mill, sistema político dominante en Occidente, sobre todo desde la caída del Muro de Berlín) ${ }^{38}$. La primera se basaba en la identidad de gobernantes y gobernados: todos aquellos que eran considerados ciudadanos (quedaban fuera las mujeres, los extranjeros y los esclavos) participaban directamente en la esfera pública, tomando conjuntamente las decisiones políti$\operatorname{cas}^{39}$. Dicho de otro modo, no existía separación entre sociedad y Estado, dedicándose aquéllos a la gestión de la cosa pública: esa y no otra era la auténtica virtud, cumpliendo en la práctica lo que el término demokratia significaba: gobierno (kratos) del pueblo (demos). En virtud de tal extremo, la mayor parte de cargos públicos, políticos o magistraturas se ejercían por sorteo, sin que tuviera mayor relevancia el mecanismo de las elecciones como procedimiento legítimo para el ejercicio de los mismos ${ }^{40}$. La segunda acepción, tal y como nos dice Giovanni Sartori, es enteramente diferente, ya que no se basa en el ejercicio directo del poder, sino que se centra, sobre todo, en la elección y selección de representantes, hecho que la diferencia de forma radical de uno de los enemigos de dicho régimen: la autocracia ${ }^{41}$. Además, otra noción característica es el lugar en la cúspi-

A. GREPPI, Concepciones de la democracia en el pensamiento político contemporáneo, Madrid, Trotta, 2006, en especial su capítulo VI, «Democratizar la democracia: conflicto y diferencia», pp. 123-146).

38 A. Garrorena Morales, voz «Democracia», en A. Montoya Melgar (dir.), Enciclopedia Jurídica Civitas, Madrid, Civitas, 1995, p. 2100. Para un repaso en profundidad de las bases teóricas que han ayudado a perfilar la democracia moderna vid. J. ABELLÁN, «El concepto moderno de democracia», en L. A. García Moreno y G. Tortella (eds.), La democracia ayer y hoy, Madrid, Gadir, 2008, pp. 149-223.

39 Respecto a la mujer ateniense, existen estudios que observarían algo parecido a una ciudadanía femenina sometida a dos requisitos: de un lado, que su nacimiento fuera atestiguado por parientes; de otro, contraer matrimonio con varón, hecho auténticamente determinante de aquel estatus. Aun así, la sociedad del momento seguía circunscribiendo el ámbito típicamente femenino al hogar, dado que por sí misma — sin hombre de por medio- no era tenida en consideración. Vid. D. Romero GonZÁlez, «Pericles y la Ley de Ciudadanía del 451-450 a. C.», en P. PÉREz CANTó (ed.), De la democracia ateniense a la democracia paritaria, Barcelona, Asociación Española de Investigación de Historia de las Mujeres-Icaria, pp. 13-23.

${ }^{40}$ Vid. B. MAnin, Los principios del gobierno representativo, Madrid, Alianza, 2006, en especial su capítulo I, «Democracia directa y representación: la selección de cargos públicos en Atenas», pp. 19-58. El tema de las elecciones por sorteo ha recobrado cierto impulso. Vid. E. AlBI, «Cargos por azar», El Cronista, núm. 65 (2017), pp. 4-16, y D. van ReYBroucK, Contra las elecciones. Cómo salvar la democracia, Madrid, Taurus, 2017.

${ }^{41}$ G. SARTORI, Teoría de la democracia, vol. II, Los problemas clásicos, Madrid, Alianza, 1987, pp. 337 y ss. Una de las corrientes que más ha incidido en la importancia de la selección de los representantes ha sido la denominada democracia mínima o democracia procedimen- 
de que ocupa la libertad política; el mundo clásico no acabó de conocer tal idea —al menos en su actual significado, potencialidad y desarrollo-, como parece que tampoco tuvo oportunidad de desarrollar un sistema de derechos al uso, cuestiones ambas que parecen irrenunciables en el seno de cualquier democracia madura. A todo ello se le añade la necesaria intermediación y canalización que los partidos políticos hacen de las diferentes opciones políticas, tarea sin la cual las democracias modernas tendrían serios problemas de funcionamiento. Tal y como dijo Manuel García Pelayo, la democracia de nuestro tiempo es necesariamente una democracia de partidos ${ }^{42}$.

Recordemos ahora algunos planteamientos que intentaron hacer más participativas las democracias representativas modernas dotándolas de mayores dosis de participación. Un ejemplo clásico es el de Kelsen, quien aportó ideas muy interesantes allá por el periodo de entreguerras: primero, que la democracia parlamentaria — con todos sus defectos- es el sistema irrenunciable a seguir, y segundo, que nada obsta a tal fin la adopción y regulación de ciertos institutos de democracia participativa directa que fortalecerían el sistema ${ }^{43}$. Recordemos también a MacPherson, quien se propone desentrañar cuál sería la forma idónea de que existiera una mayor dosis de participación política dentro también de las democracias representativas ${ }^{44}$. Acaba encontrando la misma en una combinación entre un sistema piramidal (democracia directa en la base y democracia delegada en todos los niveles por encima de ella) y un sistema de partidos en constante competición, mezcla tan inevitable como positivamente deseable, a juicio del autor ${ }^{45}$.

Este largo excurso proviene del paralelismo observable entre sendas visiones (la participativa y la paritaria): ambas se apoyan en las mismas para aumentar la participación sin cuestionar sus bases. De algún modo se

tal. Según la misma, la clave del sistema reside en garantizar que exista un procedimiento limpio, transparente y sólido a la hora de que la ciudadanía elija a sus gobernantes. Cumplidas tales exigencias el requisito democrático se vería satisfecho. Vid. J. A. Schumpeter, Capitalismo, socialismo y democracia, Madrid, Folio, 1996, pp. 342 y ss. Algunos sectores doctrinales no han dudado en exponer que la misma democracia paritaria combatiría tal idea minimalista de democracia. Vid. A. SiERRA GonZÁLEZ, «La democracia paritaria y las paradojas ocultas de la democracia representativa», en A. SierRA GonZález y M. ${ }^{a}$ P. DE LA Nuez Ruiz (eds.), Democracia paritaria (aportaciones para un debate), Barcelona, Laertes, 2007, p. 194.

${ }^{42}$ M. García Pelayo, «El Estado de partidos», en Obras Completas, 2. ${ }^{a}$ ed., Madrid, CEPC, 2009.

${ }^{43}$ H. Kelsen, De la esencia y valor de la democracia, Oviedo, KRK, 2006, p. 114.

44 Vid. C. B. MacPherson, La democracia liberal y su época, Madrid, Alianza, 2003, p. 122.

45 Ibid., p. 145. 
observa un déficit cuantitativo, y gracias a una mayor participación, éste tiende a desaparecer progresivamente ${ }^{46}$.

La quinta y última característica es la democracia paritaria como democracia deliberativa, haciendo buenos los postulados de Habermas y Elster ${ }^{47}$. No (sólo) se trata de que las mujeres participen más, sino de que participen mejorando así la calidad de la democracia ${ }^{48}$. Para estos autores, en las democracias modernas confluyen hasta tres procedimientos a la hora de tomar decisiones colectivas: la deliberación (debate racional y argumentado entre ciudadanos activos), la negociación (transacción en la que se ofrecen promesas y existen amenazas ciertas) y la votación en sí misma (suma de las opciones individuales sin que los participantes se comuniquen entre sí). Ocupada la arena política (el espacio público) por una ciudadanía en ebullición, los potenciales afectados por la decisión final canalizan su participación mediante diferentes mecanismos, organizaciones e instituciones, informándose previamente de los asuntos a discutir. Siguiendo a Velasco Arroyo, con la noción de democracia deliberativa se subraya la necesidad de que haya un alto grado de reflexión y debate, tanto por parte de la ciudadanía como por parte del legislativo y del ejecutivo ${ }^{49}$.

No parece descabellado concluir que, apoyándose en estas tesis, la inclusión masiva de la mujer en el debate político en general (y parlamentario en particular) supondría también un aumento en y de la discusión pública, trasladando ciertos beneficios a los regímenes democráticos actuales. Por un lado, dado que la participación autónoma y libre de las afectadas contribuiría a complementar en mayor medida esas esferas (pública

${ }^{46}$ No obstante, no se suele profundizar más allá de un nivel elemental. Vid. G. SARTORI, Teoría de la democracia, vol. I, El debate contemporáneo, Madrid, Alianza, 1987, pp. 150 y ss. Incluso investigadoras de fuste - declaradas partidarias del argumento de la diferencia, por otro lado- observan que se producen tensiones adicionales cuando aumenta la concurrencia política de la mujer. Vid. A. PHILlIPS, «Qué tiene de malo la democracia liberal», en R. DeL Águila y F. Vallespín (eds.), La democracia en sus textos, Madrid, Alianza, 1998, p. 333 y ss.

47 Vid. J. Habermas, Facticidad y validez, Madrid, Trotta, 2005, en especial sus capítulos VII, «Política deliberativa: un concepto procedimental de democracia», pp. 363-406, y VIII, «Sobre el papel de la sociedad civil y de la opinión pública política», pp. 407-468, y J. Elster, La democracia deliberativa, Madrid, Gedisa, 2001, pp. 18 y ss.

${ }^{48}$ Vid. S. H. Williams, «Equality, Representantion and Challenge to Hierarchy: Justifying Electoral Quotas for Women», en S. H. Williams (ed.), Constituting Equality. Gender Equality and Comparative Constitutional Law, New York, Cambridge University Press, 2009, pp. 53-72.

49 J. C. Velasco Arroyo, «Acerca de la democracia deliberativa. Fundamentos teóricos y propuestas prácticas», Asamblea. Revista Parlamentaria de la Asamblea de Madrid, núm. 9 (2003), p. 7. Puede consultarse también el interesante estudio de C. Rico Motos, Deliberación parlamentaria y democracia representativa, Madrid, Congreso de los Diputados, 2016. 
y privada) que han aparecido tradicionalmente escindidas, siendo, además, un elemento clave para la lucha contra la discriminación por razón de sexo $^{50}$. Por otro lado, la deliberación supone aceptar la posibilidad de modificar los intereses y posiciones iniciales a través del intercambio racional de argumentos entre las partes, lo que permitiría a los representantes acoger y defender la causa femenina ${ }^{51}$.

\section{Caracteres prácticos}

En la práctica, la democracia paritaria se ha intentado realizar a través de las cuotas electorales, medidas que plasman porcentajes mínimos de mujeres en las listas electorales y que buscan su llegada al escaño.

Las cuotas han alcanzado rango universal, expandiéndose por todo el mundo. Así lo atestiguan diversos estudios que versan sobre su origen y diseño; sobre su implementación práctica; sobre quiénes, cómo y porqué impulsan la medida; sobre el análisis de su constitucionalidad ${ }^{52}$; acerca de su evolución y perspectivas futuras, y un largo etcétera ${ }^{53}$. Valga resumir dos aspectos clave: los motivos para adoptar las mismas y el tipo de cuota ${ }^{54}$.

Dentro de los primeros se hace hincapié, en primer lugar, en la existencia de una importante movilización femenina ejerciendo presión social

50 B. Rodríguez RuIz, «Discriminación y participación», Revista de Estudios Políticos, núm. 110 (2000), pp. 205 y 206.

${ }^{51}$ A. PHILLIPS, «La política de la presencia...», op. cit.,pp. 255 y 256.

52 Se intentó resumir el debate en I. Álvarez Rodríguez, Democracia equilibrada versus Democracia representativa, Madrid, Congreso de los Diputados, 2012.

53 A día de hoy, más de noventa países aplican algún tipo de cuota. Vid. T. DošEK et al. (eds.), Women, Politics, and Democracy in Latin America, New York, Palgrave Macmillan, 2017; M. Lena Krook y P. Zetterberg (eds.), Gender Quotas and Women's Representation. New Directions in Research, London-New York, Routledge, 2016; F. Thames y M. Williams, Contagious Representation Women's Political Representation in Democracies around the World, New York, New York University Press, 2013; M. LenA, Quotas for Women in Politics. Gender and Candidate Selection Reform Worldwide, New York, Oxford-University Press, 2009, y D. Dahlerup (ed.), Women, Quotas and Politics, New York, Routledge, 2006.

${ }^{54}$ Vid. M. Lena Krook, Quotas for Women in Politics..., op. cit.; M. Lena KrooK, J. Lovenduski y J. SQuires, «Western Europe, North America, Australia and New Zealand. Gender Quotas in the Context of Citizenship Models», en D. Dahlerup (ed.), Women, Quotas and Politics, New York, Routledge, 2006, pp. 194-221, y M. Lena Krook, J. Lovenduski y J. Squires, «Gender Quotas and Models of Political Citizenship», paper presentado en la Conferencia Nacional de la Midwest Political Science Association, Chicago (Illinois), 3-6 de abril de 2008, pp. 1-42, disponible en bttp://krook.wustl.edu/pdf/KLS_MPSA_2008.pdf (consultado el 22 de octubre de 2017). 
y política a su favor; en segundo término, por motivos estratégicos de los partidos (se produce un «efecto imitación», en tanto en cuanto las formaciones no quieren perder posibles caladeros de votos); el tercer motivo se refiere a la realización efectiva del principio de igualdad de género en el ámbito representativo, y en cuarto y último lugar, porque constituye una exigencia jurídica internacional ${ }^{55}$.

Dentro de los segundos, y aun aceptando lo relativo de cualquier clasificación pretendidamente exhaustiva ${ }^{56}$, destacan cuatro tipos ${ }^{57}$. El primer tipo, los puestos reservados (reserved seats), quizá el ejemplo más extremo de cuota, ya que reserva directamente una serie de escaños en la Cámara para las mujeres. Esta opción, mundialmente minoritaria, puede ser rastreada en determinados países africanos o asiáticos ${ }^{58}$. El segundo tipo, la cuota legal/legislativa (legislative quota), cuya característica principal es su previsión en una norma jurídica de rango legal elaborada por el Parlamento en cuestión. Las notas básicas de esta forma son tres: establece un nuevo criterio a la hora de que los partidos realicen la selección de candidatos, afecta a la composición de las listas del partido (en los sistemas proporcionales) y a los candidatos elegibles (sistemas mayoritarios), y, por último, se suelen adoptar previendo algún tipo de sanción en caso de incumplimiento. Uno de sus principales focos de implementación es la región latinoame-

55 Alguna de estas razones también ha sido apuntada por T. VerGE, «Gendering Representation in Spain: Opportunities and Limits of Gender Quotas», Journal of Women, Politics E Policy, núm. 31 (2010), pp. 166-190.

56 Tal y como acreditan otros estudios, como los de M. MATEO-DíAz, «Searching for the Panacea of Long-Term Equality: on the Art of Combining Quick-Fix Solutions and Structural Measures to Increase the Presence of Women in Parliament», EUI Working PaperRSCAS, núm. 7 (2004); G. CERRINA FERONI, «Democrazia nei partiti e pari opportunità. Una rassegna comparata», Diritto e Societá (nuova época), núm. 1 (2009), pp. 147-189, y R. SÉNAC-SLAWINSKI, «Des quotas légaux et partisans á la parité: panorama des stratégies en Europe», Informations Sociales, vol. 1, núm. 151 (2009), pp. 30-39. Buena parte de la doctrina española acepta, no obstante y con carácter general, un esquema tripartito (decisión voluntaria de los partidos-decisión del legislador-decisión del poder constituyente). Vid. M. GurRera Roig, «Veinticinco años de paridad política hombre-mujer», Revista de Derecho Político, núm. 58-59 (2003-2004), p. 275. Vid. también D. Dahlerup et al., Atlas of Electoral Gender Quotas, Stockholm, IDEA, 2013.

57 Vid. M. LenA KRoOK, Quotas for Women in Politics..., op. cit., pp. 5 y ss.

58 Valga como muestra lo que ocurre en Burundi, por un lado, y en Taiwán, por otro. En el primero, el art. 164 de su Constitución establece una reserva del 30 por 100 de los escaños parlamentarios para la mujer, mientras que en el segundo, su norma fundamental también contempla tal previsión para las dos Cámaras, emplazando a la ley para que fije porcentajes concretos, que han venido oscilando entre el 10 y el 25 por 100. Vid. http://www. quotaproject.org/ (consultado el 22 de octubre de 2017). Vid. D. DAHLERUP et al., op. cit. en nota 56, pp. 75 y ss. y 199 y ss. 
ricana, a pesar de que entre los países que la forman existen ciertas peculiaridades ${ }^{59}$. Reseñable es que la misma concita más apoyos que la anterior forma, sin alcanzar el nivel de desarrollo de otras que a continuación se verán. El tercer tipo sería la cuota de partido (party quota), donde los partidos son quienes, de motu proprio, implementan la misma (cada uno a su forma). También aquí se modifican los criterios existentes en el seno de las organizaciones a la hora de elegir a los futuros representantes lo que, por extensión, afecta a la configuración electoral sobre la forma de selección (en ambos sistemas, proporcional y mayoritario). A diferencia de lo que ocurría anteriormente, las sanciones por transgredir la norma no siempre están estipuladas. Cierta parte del mundo occidental se ha decantado por esta opción, sobre todo, y como ya se decía en el primer capítulo, teniendo especial protagonismo los partidos verdes y socialdemócratas. En suma, estaríamos ante una cuota proveniente del partido, pero pensada para operar fuera del mismo. El cuarto y último tipo es el de cuota suave (soft quota). La principal similitud con el anterior esquema se centra en que esta también es adoptada de forma voluntaria por los partidos políticos, pero a partir de ahí difiere en todo lo demás. Estaríamos en presencia del establecimiento de objetivos informales y recomendaciones respecto a la elección de candidatos en el seno de la formación política. Además, donde opera este modelo es en la selección de cargos en el interior del partido, sin existir — salvo contadas excepciones- sanción alguna en caso de incumplimiento ${ }^{60}$. Nos encontramos, por ende, ante un porcentaje que desplegaría sus efectos a la

59 Peculiaridades que tienen que ver con el tipo de cuota o la formulación de la misma; en definitiva, y a pesar de que cada país varía en tales cuestiones, la tendencia general apreciable en el continente parece clara: allá donde se han aplicado estas medidas, la representación de la mujer ha aumentado de forma más rápida que sin hacer uso de ellas. Vid. M. Ríos Tobar, Cuotas de género: democracia y representación, Santiago de Chile, FLACSO, 2006; M. LEÓN (ed.), Nadando contra la corriente. Mujeres y cuotas políticas en los países andinos, Bogotá-Bolivia-Ecuador, UNIFEM-RA-UNFPA-Escuela de Estudios de Género de la Universidad Nacional de Colombia-Instituto de Estudios Peruanos-CIDEM-FLACSO, 2005; T. DošEK et al. (eds.), Women, Politics, and Democracy..., op. cit.; M. Lena Krook y P. ZetTeRBERG (eds.), Gender Quotas and Women's Representation..., op. cit.; F. ThAmes y M. WILliams, Contagious Representation Women's Political Representation..., op. cit.; M. KROOK, Quotas for Women in Politics..., op. cit., y D. DAhleruP (ed.), Women, Quotas... op. cit.

${ }^{60}$ Las formas de plasmar de forma efectiva la cuota son varias, como se verá posteriormente, pero ahora interesa reseñar los aspectos más problemáticos; de un lado, que se refieran en exclusiva a las mujeres y, de otro, que sean obligatorias. Parte de la doctrina que ha estudiado el asunto parece decantarse por unos porcentajes temporales, negociables entre los diferentes niveles partidistas. Vid. J. LovENDUSKI, «Representación política: dinámica de género y partidos», en E. URIARTE y A. ElizONDO (coords.), Mujeres en política, Ariel, Barcelona, 1997, p. 125. 
hora de elegir los cargos y puestos internos, no extramuros de la formación política. A pesar de que son éstas las que parecen gozar del apoyo mayoritario en las democracias representativas occidentales, en numerosos casos ni tan siquiera aparecen formuladas con el término cuotas $^{61}$.

Finalmente, se distinguen dos grandes formas de enunciarlas: unidireccional y bidireccionalmente. La primera se refiere a la cuota contemplada sólo a favor de la mujer. En la segunda la medida se refiere a los dos sexos. Las primeras regulaciones fueron unidireccionales, como muestran algunos ejemplos históricos, hoy casi en vías de extinción. Por ejemplo, la Ley de Cupo Femenino argentina de 1991 contemplaba un 30 por 100 obligatorio de mujeres en los puestos electivos ${ }^{62}$. Asimismo, Brasil estableció en 1997 el 25 por 100 de candidatas en las listas en las elecciones a la Cámara de Diputados ${ }^{63}$. La legislación de Nepal reserva directamente el 40 por 100 de los puestos a las mujeres candidatas ${ }^{64}$. Recientes regulaciones normativas recogen el formato bidireccional, aunque su origen también es remoto. La normativa belga de 1994 preveía que las listas electorales podían contemplar como máximo dos tercios de candidatos del mismo sexo ${ }^{65}$, mientras que la legislación italiana de 1993 (para elecciones municipales) exigía que un tercio de las candidaturas debían estar formada por candidatos pertenecientes al sexo menos representado (lógicamente, eran las mujeres) ${ }^{66}$. Quizá la forma más incisiva de este subtipo sean las listas-cremallera, donde se alterna hombre-mujer a lo largo de la misma ${ }^{67}$.

${ }^{61}$ El grado de intervencionismo público que parece presuponerse con dicha denominación no acabaría de casar con aquellos Estados en los que predomina una concepción política de la ciudadanía de corte liberal, de ahí que sea éste el medio preferido para intentar alcanzar mayores dosis de igualdad entre sexos. Vid. M. Lena KroOK, J. Lovenduski y J. SQUIRES, «Gender quotas and models...», op. cit., p. 199.

${ }^{62} \mathrm{Vid}$. M. ${ }^{a}$ L. FEMENÍAs, «Cuotas, ¿un camino hacia la paridad?», en A. SiERra GonZÁLez y M. ${ }^{a}$ P. DE LA Nuez Ruzz (eds.), Democracia paritaria (aportaciones para un debate), Laertes, Barcelona, 2007, p. 37.

${ }_{63}$ Vid. http://www.quotaproject.org/displayCountry.cfm? CountryCode=BR (consultado el 23 de octubre de 2017).

${ }^{64}$ Vid. http://www.quotaproject.org/displayCountry.cfm? CountryCode=NP (consultado el 23 de octubre de 2017).

${ }_{65}$ P. MeIER, «Experiencias de reformas electorales en algunos países de la Unión Europea: iniciativas en Bélgica y Portugal», en P. SAAVEDRA (dir.), Hacia la democracia paritaria. Análisis y revisión de las leyes electorales vigentes, Madrid, CELEM, 1999, p. 207.

${ }^{66}$ Ambos países han visto cómo el proceso de implementación de estas medidas ha estado jalonado de importantes polémicas constitucionales. Sobre el asunto belga vid. S. Drooghenbroeck e I. Hachez, op. cit., nota 81. Para el caso italiano vid. G. Brunelli, «La vicenda italiana: le quote riservate alle donne nelle liste elettorali», en Donne e Politica, Bologna, Il Mulino, 2006, pp. 47 y ss.

${ }_{67}$ Para el caso español vid. B. Aldeguer Cerdé, «El desarrollo de la democracia pari- 


\section{FACTORES DE INFLUENCIA}

La adopción de las técnicas aludidas no explica, por sí sola, la mayor o menor presencia de mujeres en las instituciones representativas. Existen algunos factores que deben ser tenidos en cuenta ${ }^{68}$.

\section{Factores sociales y culturales}

Estos factores parten de la dicotomía público-privado. Mientras que el hombre quedaría ligado y llamado a ejercer la primera tarea, la mujer vendría relegada a la segunda; la consecuencia que de ello se deriva es un estado de cosas en el que ellas no tienen competencia para ejercer las responsabilidades públicas, debiendo circunscribir su quehacer a la esfera doméstica en aras de cumplir con uno de sus cometidos básicos: la asunción y desarrollo del rol reproductivo ${ }^{69}$.

Ahondando en esa idea, los estereotipos asociados a cada género se verían consolidados y transmitidos por la imagen estigmatizada que los medios de comunicación ofrecen a diario de dicha situación, perpetuando las diferencias que obstaculizan el acceso de la mujer a las funciones políticas en general y a las parlamentarias en particular. Es por ello que una de las posibles soluciones que se aportan para intentar invertir esta tendencia es adoptar planes públicos de sensibilización, educación y concienciación

taria en la normativa autonómica y electoral de las Comunidades Autónomas españolas», Revista de Investigaciones Políticas y Sociológicas, núm. 2 (2015), pp. 33-72; I. M. a ABELLÁN MATESANZ, «La modificación de las leyes electorales a la luz del principio de igualdad: las listas cremallera», Revista de Estudios Autonómicos, núm. 2-3 (2002-2003), pp. 147-161, y R. SERRa CRISTÓbal, «La presencia de la mujer en los Parlamentos autonómicos. La efectividad de las medidas de paridad adoptadas por los partidos políticos y por el legislador», Revista de Estudios Politicos, núm. 141 (2008), pp. 177 y ss. Una propuesta reciente para introducir un sistema de «triple cremallera» en V. RAMírez GonZález y A. LóPEZ CARMoNA, «Mejora de la paridad de género en el Congreso de los Diputados», Revista de Estudios Sociológicos, núm. 23 (2015), pp. 95-116.

68 Vid. J. Ballington, Equality in Politics: A Survey of Women and Men in Parliaments, Inter-Parliamentary Union, Reports and Documents, núm. 54 (2008).

${ }^{69}$ Vid. A. Marrades Puig, «Los derechos políticos de las mujeres: evolución y retos pendientes», Cuadernos de la Cátedra Fadrique Furió Ceriol, núm. $36 / 37$ (2001), p. 197. El rol reproductivo femenino también ha sido estudiado en relación a las dificultades que apareja dicha condición con el desempeño de las tareas parlamentarias. Vid. B. TOMÁs, «Hacia un Parlamento paritario: en particular, la situación de maternidad de las parlamentarias», en I. Delgado Sotillos (ed.), Alcanzando el equilibrio : el acceso y la presencia de las mujeres en los Parlamentos, Valencia, Tirant lo Blanch, 2011, pp. 181-205. 
a la ciudadanía, con un objetivo claro: las mujeres pueden llevar a cabo las tareas parlamentarias de modo tan efectivo como los hombres ${ }^{70}$.

\section{Factores políticos y electorales}

El segundo de los bloques se centra en los partidos políticos y los sistemas electorales ${ }^{71}$. Respecto a las formaciones partidarias, especialmente relevante es el orden que el partido decida en la candidatura electoral en cuestión (si es que puede hacer tal cosa), así como la mayor o menor influencia de las elites (mayoritariamente masculinas) en el proceso decisorio $^{72}$. En cuanto al sistema electoral, la conclusión es poco discutida: con un sistema proporcional la mujer alcanza mayores réditos electorales que con uno mayoritario, donde las posibilidades de ser elegidas decrecen ${ }^{73}$.

Un aspecto interesante es la relación entre el modelo político y la adopción de cuotas. Se identifican hasta tres grandes modelos, junto a un cuarto que sería una mezcla de los anteriores ${ }^{74}$. El primero de ellos

70 Vid. J. Ballington, Equality in Politics..., op. cit., p. 19. El rol de madre -inescindible de la condición femenina- apareja ciertas cargas a la hora de desarrollar el mandato representativo. Desde la doctrina se han propuesto mecanismos para superar las mismas, tales como el voto delegado, el voto en ausencia o la sustitución temporal de la afectada, trasladable a supuestos homologables (como la baja por paternidad, por ejemplo). Vid. B. Tomás, «Hacia un Parlamento paritario...», op. cit., pp. 184 y ss.

${ }^{71}$ El informe hace también mención a dos bloques más: el tema de la financiación de las campañas electorales y la política de cuotas en sí misma. Dado que de alguna manera el primero quedaría subsumido en los condicionantes político-institucionales y del segundo hemos dado (y seguiremos dando) cuenta, nos remitimos al cuerpo del trabajo en lo que a los mismos se refiere.

${ }^{72}$ El trabajo de la politóloga norteamericana Pipa Norris es especialmente ilustrativo en esta materia. Su principal cometido es estudiar todos aquellos factores que afectan al proceso de reclutamiento legislativo protagonizado por los partidos, es decir, la ocupación efectiva de cargos de representación política. En ese sentido, destaca fundamentalmente tres -el sistema legal, el sistema electoral y el sistema de partidos- como principales condicionantes a la hora de seleccionar a los futuros representantes, lo que a su vez proyecta a las diferentes minorías políticas y, en concreto, a la mujer. Vid. P. NORRIS, «Procesos de reclutamiento legislativo: una perspectiva comparada», en E. URIARTE y A. ELIZONDO (coords.), Mujeres en política, Barcelona, Ariel, 1997, pp. 149-181.

${ }_{73}$ Algunos estudios apuntan que las posibilidades de que resulten elegidas se sitúa en torno al doble en los sistemas proporcionales respecto a los mayoritarios. Vid. P. NoRRIS, «The Impact of Electoral Reform on Women's Representation», Acta Politica, núm. 0 (2006), p. 5. Para una óptica global del problema vid. M. Tremblay (ed.), Women and Legislative Representation. Electoral Systems, Political Parties and Sex Quotas, New York, Palgrave Macmillan, 2008.

${ }^{74}$ Vid. M. Lena Krook, J. Lovenduski y J. SQuires, «Gender quotas and models...», op. cit., pp. 10 y ss. 
es el modelo liberal, cuyo valor nuclear sería el individualismo. El principal conflicto que surge en estos sistemas proviene de la creencia de que la responsabilidad individual tiene mucho que ver con la desigualdad, abogando por no intervenir directamente en la selección de candidatos. El segundo es el modelo republicano, que pivotaría sobre otro valor clave: el universalismo. En ese sentido, la controversia aquí producida se centra en la (in)adecuación de la representación descriptiva, debido a que se propugna la superación de las identidades concretas en aras de la representación de los intereses del conjunto de la ciudadanía. El tercero es el modelo consociacional-corporatista, en el que el principio básico de convivencia es el pacto social entre los diferentes grupos sociales, políticos y económicos ${ }^{75}$. La dicotomía que se produce aquí se circunscribe al que se quiere considerar el principal cleavage: por un lado, el étnico-lingüístico; por otro, el de género. Dicho de otra forma, existiría la duda de si el género habría alcanzado la operatividad, el desarrollo y la potencialidad del anterior. Finalmente tendríamos un modelo bíbrido, que sería una mezcla de todos ellos.

De ese modo, Estados Unidos, Canadá o el Reino Unido serían buenas muestras del primero; Francia lo sería del segundo; España, Holanda, Bélgica, Italia o Alemania ejemplificarían el tercero, y Finlandia, Dinamar$\mathrm{ca}$, Suecia, Islandia y Noruega responderían al cuarto. Las medidas menos incisivas (soft quotas) serían características del primero, mientras que las de partido (party quotas) se implementan en mayor medida en el tercero ${ }^{76}$.

Si tuviéramos que resumir el asunto podríamos decir lo siguiente. En primer lugar, la cultura política es especialmente importante. El grado de sensibilidad y de asunción del postulado igualitario tiene mucho que ver

75 Conviene no confundir corporatismo con corporativismo. El primero alude a la presencia hegemónica de las grandes corporaciones en las sociedades contemporáneas, que operan como actores colectivos privilegiados para la intermediación social. Ése es al que se refiere, creemos, la profesora Krook. Por el contrario, el segundo tiene básicamente tres acepciones: la primera se refiere a la doctrina económica que preconiza la estructura vertical de las distintas profesiones; la segunda hace alusión a la doctrina política desarrollada en el periodo de entreguerras mediante la que se pretendía ordenar las sociedades a través de corporaciones controladas por el Estado que venían a sustituir a partidos y sindicatos, y la tercera se refiere a la pauta de comportamiento caracterizada por defender a ultranza los intereses de un determinado grupo socioprofesional. Vid. E. MoYano EstRada, voces «Corporatismo» y «Corporativismo», en S. Giner, E. LAmo DE EsPinosa y C. Torres (eds.), Diccionario de sociología, 2. ${ }^{a}$ ed., Madrid, Alianza, 2006, pp. 174 y 175.

${ }^{76}$ Aunque se aprecia la introducción, en este último, de acciones positivas con mayor mordiente (legislative quotas). Vid. M. LENA KROOK, J. Lovenduski y J. SQuires, «Gender quotas and models...», op. cit., p. 33. 
con alcanzar niveles estimables de participación política. A su vez, dicho parámetro cultural se ve ampliamente influenciado por una cuestión social: el relevo generacional; de ese modo, y aunque varía en función del país estudiado, a finales del siglo xx y comienzos del xxI parece que la igualdad de género es algo aceptado mayoritariamente por la sociedad y por las principales organizaciones sociales y políticas ${ }^{77}$. Esto se ha traducido en una presencia femenina creciente en las élites políticas a nivel general y en los partidos políticos a nivel particular; organizaciones estas últimas que son — siquiera parcialmente - reflejo de las sociedades democráticas de las que provienen. Es el feedback de género. Dicho feedback se muestra en dos ámbitos: el número de afiliadas y militantes, de un lado, y el desempeño de cargos internos en el partido, de otro. Tanto en un caso como en otro, la tendencia se consolida a favor de la mujer ${ }^{78}$.

La ideología de cada partido también tiene un grado de influencia nada desdeñable. En ese sentido se observa que el colectivo femenino tiene mayor presencia en los órganos de partidos de izquierda que en los de derecha, criterio que se muestra inapelable cuando acudimos a los partidos de extrema derecha y a aquellos englobados en la izquierda post-mayo del 68 (en concreto, los ecologistas). Lejos de ser baladí, esto último parece ser un requisito de gran importancia, en tanto en cuanto tratamos con los puestos que conducirían, a su vez, a la obtención del mandato representativo ${ }^{79}$.

Respecto a la influencia del sistema electoral, los principales trabajos elaborados en la materia concluyen que una mayor representación femenina se consigue gracias a un esquema proporcional, mientras que el mayoritario perjudica la consecución de dicho objetivo ${ }^{80}$. Como es sabido, en un

77 A. Elizondo, «Partidos políticos y mujeres», en E. URiarte y A. Elizondo (coords.), Mujeres en politica, Barcelona, Ariel, 1997, p. 97.

${ }^{78}$ E. URiarte, «Las mujeres en las elites políticas», en E. URIarte y A. Elizondo (coords.), Mujeres en política, Barcelona, Ariel, 1997, pp. 56 y ss.

79 E. Uriarte y C. Ruiz, «Mujeres y hombres en las elites políticas españolas: ¿diferencias o similitudes?», Revista Española de Investigaciones Sociológicas, núm. 88 (1999), p. 218. Un estudio publicado en nuestro país en 1982 mostraba ya cómo el factor ideológico no sólo condicionaba la presencia femenina en el interior del partido, sino también en las listas que la formación presentaba a los diferentes procesos electorales. Comunistas y socialistas presentaban unos índices muy superiores a lo que ocurría respecto a burgueses y católicos. Vid. F. G. Castles, «La representación de la mujer en los órganos legislativos», Revista de Estudios Políticos, núm. 29 (1982), pp. 215 y ss.

80 Vid. M. P. JonEs, «El sistema de cuotas y la elección de las mujeres en América Latina: el papel fundamental del sistema electoral», en P. SAAVEDRA (dir.), La democracia paritaria en la construcción europea, Madrid, CELEM, 2000, pp. 35-47, y R. MATLAND, «El impacto diferencial de los sistemas electorales en la representación política de las mujeres», en P. SAAVEDRa (dir.), Hacia la democracia paritaria. Análisis y revisión de las leyes electorales 
sistema mayoritario las circunscripciones suelen ser uninominales, mientras que en el modelo proporcional son plurinominales. Esas y otras investigaciones señalan que el segundo tipo propicia una mayor inclusión de la mujer en la institución representativa ${ }^{81}$. Respecto a las listas electorales, debe tenerse en cuenta la posición u orden que ocupan, ya que no son pocos los casos en los que se ha utilizado la inclusión femenina como reclamo electoral, reservando los puestos que tenían visos de ser elegidos a candidatos masculinos ${ }^{82}$. Parece que el objetivo se cumple mejor con listas cerradas y bloqueadas, pero tampoco es malo operar con listas cerradas y desbloqueadas (o lo que es lo mismo, con voto preferencial mediante el que selecciona a candidatos concretos), tal y como ilustran determinados casos de Derecho comparado ${ }^{83}$.

Todo ello se conjuga en la realidad de los países, que de nuevo muestra diferencias importantes en función de la división civil-law/continental law. En Estados Unidos y en el Reino Unido parece que no existe un movi-

vigentes, Madrid, CELEM, 1999, pp. 117-138. Para el caso español se pueden consultar los trabajos de T. FreixÉS SAnJuAN, «El impacto de los sistemas electorales en la representación política femenina y la introducción de medidas de acción positiva en la legislación electoral», en R. Morodo y P. DE VeGA (dirs.), Estudios de teoría del Estado y Derecho constitucional en honor a Pablo Lucas Verdú, Madrid, Servicio de Publicaciones de la Facultad de Derecho de la Universidad Complutense-UNAM, 2000, pp. 1631-1661, y de A. Ventura Franch, «Sistema electoral y género», Corts: Anuario de Derecho Parlamentario, núm. 8 extraordinario (1999), pp. 379-404. No obstante, debe tenerse en cuenta que en función del país analizado tal aseveración puede verse matizada, como ocurre en el caso de Reino Unido. Vid. S. Childs, R. Campbell y J. Lovenduski, «The Mother of All Parliaments: Westminster's Male Face», en M. Tremblay (ed.), Women and Legislative Representation. Electoral Systems, Political Parties and Sex Quotas, New York, Palgrave Macmillan, 2008 , p. 53.

${ }_{81}$ Vid. A. Elizondo, «Partidos políticos y mujeres», op. cit., pp. 98 y 99. Otros autores sostienen, por el contrario, que la influencia negativa de un tamaño reducido de la circunscripción electoral es escasa. Para el caso de la Cámara Baja española vid. C. VALIENTE, L. Ramiro y L. Morales, «Mujeres en el Parlamento: un análisis de las desigualdades de género en el Congreso de los Diputados», Revista de Estudios Políticos, núm. 121 (2003), p. 200.

${ }^{82}$ De ahí que buena parte de los sistemas promocionales recientes se preocupan por garantizar la presencia de la mujer en determinados tramos de la propia lista. Sirva como ejemplo el caso español, en concreto el modificado art. 44 bis, apartado 2, LOREG, cuando dice que: «También se mantendrá la proporción mínima del 40 por 100 (de ambos sexos) en cada tramo de cinco puestos».

${ }^{83}$ Se está aludiendo a los casos de Finlandia, Noruega y Holanda. Vid. T. Freixés SANJUÁN, «El impacto de los sistemas electorales...», op. cit., pp. 1645 y ss. En contra de tal aseveración se muestran R. MATLAND, «El impacto diferencial de los sistemas electorales...», op. cit., pp. 134 y 135, y G. D. SCHмIDT, «The Election of Women in List PR Systems», Electoral Studies, núm. 28 (2008), pp. 190-203. Para el caso español puede verse A. Pérez Miras, «El régimen electoral español en busca de la democracia paritaria», Revista de Derecho Electoral, núm. 22 (2016), pp. 141-160. 
miento paritario sólido. Las principales iniciativas que se han tomado en ambos lares discurren, en gran medida, por cauces partidarios - si acaso en el Reino Unido con una mínima intervención legislativa en la materia desde el año 2002-, quizá fruto de concepciones liberales fuertemente arraigadas ${ }^{84}$. Por su parte, en el modelo continental-europeo sí han existido prolijos procesos paritarios, todavía vivos en la actualidad. Esto se ilustra cuando se observa que las acciones paritarias han llegado hasta el nivel constitucional, bien porque su adopción ha implicado la reforma de la Norma Fundamental (caso de Bélgica, aunque también de Italia y Francia), bien porque la cuestión ha llegado a conocimiento del Tribunal Constitucional correspondiente o bien por ambos extremos (como ha sucedido en Italia y en Francia) ${ }^{85}$. Otros han decidido centrar en las leyes de paridad su modelo de igualdad (caso de nuestro país) y, en fin, algunos más han circunscrito estas medidas a lo que los partidos hayan decidido hacer (o no hacer) al respecto. Son, como puede imaginarse, los países nórdicos, que optimizan mediante aquéllos un marco legal no especialmente incisivo en estas cuestiones, quizá porque allí la filosofía igualitaria se encuentra más que asentada ${ }^{86}$.

\section{LA DEMOCRACIA PARITARIA 2.0}

La democracia paritaria original, tal y como la acabamos de ver, se ha visto sometida a nuevas formulaciones ${ }^{87}$. Veamos.

La base de las mismas se centra en la importancia de considerar la democracia paritaria como una exigencia estructural del sistema. Si no es

${ }^{84}$ Para el caso de Estados Unidos puede verse J. Manning, I. BRudnick y C. SHogan, «Women in Congress: Historical Overview, Tables, and Discussion», Congressional Research Service, abril de 2017, disponible en https://www.everycrsreport.com/reports/R43244.html. Para el caso británico puede verse R. KeLLY, Women Members of Parliament, House of Commons, 2017.

${ }^{85}$ Se analizan todos ellos en M. Lena Krook y P. Zetterberg (ed.), Gender Quotas and Women's Representation..., op. cit., y en F. Thames y M. Williams, Contagious Representation Women's Political Representation..., op. cit.

86 Vid. D. Dahlerup y L. Freidenvall, «Quotas as Fast Track to Equal Representation for Women», International Feminist Journal of Politics, núm. 7, vol. 1 (2005), pp. 26-48.

${ }^{87}$ Nos basamos en los trabajos de K. Celis, S. Childs, J. Kantola y M. L. Krook, «Rethinking Women's Substantive Representation», Representation, núm. 44-2 (2008), pp. 99-110; ÍD., «Constituting Women's Interests through Representative Claims», Politics E Gender, núm. 10 (2014), pp. 149-174, y D. DAHLERUP, «Representing Women. Defining Substantive Representation of Women», en M. C. Escobar-Lemmon y M. M. TAYLOR-Robinson (eds.), Representation. The Case of Women, Oxford, Oxford University Press, 2014, pp. 58-75. 
paritaria, no es democracia, se dirá ${ }^{88}$. Ya no se trata de «ayudar» o «aupar» a la mujer para que llegue al escaño y así eliminar discriminaciones individuales; la democracia (paritaria) es mucho más que eso ${ }^{89}$.

Lógicamente, el sentido de la representación política femenina cambia. En primer término, se critica la presunta unión de la representación descriptiva y la sustantiva, porque, en suma, no es un axioma el hecho de que a mayor proporción de mujeres, mayor y mejor representación de los intereses femeninos. En ese sentido Beckwith demuestra que un aumento del número de mujeres no repercute necesariamente en un aumento de las políticas públicas relacionadas con «los intereses» de las mujeres, y que, además, la nueva llegada al puesto supone hacer frente a una serie de dificultades extra derivadas del «lugar de trabajo nuevo» ${ }^{90}$. En segundo término, porque desde posturas antiesencialistas se argumenta que esos intereses femeninos ni están predeterminados, ni son cerrados u homogéneos, ni, en ocasiones y dadas las condiciones institucionales existentes, permiten que las mujeres puedan «descifrarlos»; todo ello por no mencionar la presión añadida que se pone sobre la representante, una suerte de guardiana de las esencias sometida a severo escrutinio ${ }^{91}$. Lo cierto es que nunca se ha tenido claro qué y cuáles son esos intereses femeninos. Se apuntan algunos, en ocasiones de forma muy amplia («derechos de la mujer», «estatus económico», salud», «bienestar»), en otras de forma menos amplia («asuntos relacionados con los niños», «educación», «bienestar social», «medioambiente») y en otras refiriéndose a uno o dos, a lo sumo («derechos reproductivos y sexuales», «derecho al aborto») ${ }^{92}$. Es más, algunas estudiosas llegan de este modo a reformular la noción, que de «intereses» pasan a ser «preferencias» o «asuntos» ${ }^{93}$. Ahora los «intereses femeninos» se descifran gracias al debate deliberativo: no preexisten

${ }^{88}$ Por todos vid. B. Rodríguez Ruiz y R. Rubio Marín, «De paridad, igualdad y representación en el Estado democrático», Revista Española de Derecho Constitucional, núm. 81 (2007), pp. 115-159, e íD., «La democracia como democracia paritaria», en E. BodELón y D. Heim (coords.), Derecho, género e igualdad: cambios en las estructuras jurídicas androcéntricas, vol. 1, Barcelona, Universitat Autònoma de Barcelona-Grupo Antígona, 2010, pp. 317-334.

89 Vid. O. Salazar Benítez, «Género, poder y ciudadanía», Revista Cuadernos Manuel Giménez Abad, núm. 5 (2017), pp. 60 y ss

${ }^{90}$ K. BECKWITH, «Numbers and Newness: The Descriptive and Substantive Representation of Women», Canadian Journal of Political Science, núm. 40-1 (2007), pp. 27-49.

${ }^{91}$ Vid. P. Allen y P. CutTS, «Exploring Sex Differences in Attitudes Towards the Descriptive and Substantive Representation of Women», The British Journal of Politics E International Relations, vol. 18, núm. 4 (2016), pp. 912-929.

92 Vid. J. Manning, I. Brudnick y C. SHOgan, «Women in Congress...», op. cit., p. 11.

93 Vid. K. BeCKwITH, «Plotting the Path from One to the Other: Women's Interests 
ni pueden preexistir ${ }^{94}$. La balanza oscila hacia la deliberación participativa, lo que mejoraría la calidad de la democracia. No obstante, permanece la crítica al mismo; crítica que ahora deja la sensación de un cierto agotamiento del modelo, un cierto desahogo contra un sistema que no acaba de lograr la inclusión real ${ }^{95}$.

El marco teórico también cambia. Se llega a la conclusión de que haber estado estudiando la cuestión (únicamente) desde «la óptica de Pitkin» no permite formular las preguntas correctas. Por ejemplo, en lugar de cuestionarnos si ¿representan las mujeres a las mujeres? o si ¿marcan la diferencia las mujeres en política?, deberíamos más bien interrogarnos acerca de ¿quién reivindica actuar para y por las mujeres? El cambio en las preguntas se hace al calor de nuevas concepciones de la representación política, en concreto las que defienden Mansbridge y, sobre todo, Saward. Mansbridge defiende cuatro formas de representación (promisoria, anticipatoria, giroscópica y subrogada), relacionando la representación política femenina con la última ${ }^{96}$. La representación subrogada es la representación que realiza un representante también para los que no le votaron (se subroga - sustituye- al representante no elegido), es decir, es el representante de todos. La relación se refuerza especialmente cuando aquél comparte experiencias vitales con éstos (pertenece al mismo grupo y de dicha pertenencia se derivan diversas experiencias muy similares), desarrollando un especial sentido de la responsabilidad hacia dicho grupo. Ejemplos, además de las mujeres, podrían ser otras minorías (en Estados Unidos, la comunidad afroamericana y la comunidad polaca). Saward, por su parte, considera la representación, fundamentalmente, como un proceso de reivindicación de demandas ${ }^{97}$. En esta concepción, la representación es un complejo asunto (electoral, estético y cultural) donde intervienen multitud de actores (institucionales y no institucionales) que accionan demandas e intereses de los que considera sus representados (demandas que siempre son parciales). Poniendo en

and Political Representation», en M. C. Escobar-Lemmon y M. M. TAYlor-Robinson (eds.), Representation. The Case of Women, Oxford, Oxford University Press, 2014, pp. 19-40.

${ }^{4}$ Vid. D. DAHLERUP, «Representing Women...», op. cit., pp. 58-75.

95 Vid. R. M. Mestre i Mestre, «Ciudadanía, autonomía y participación política de las mujeres en democracia», en R. M. Mestre i Mestre e Y. Zúñiga AÑazco (coords.), Democracia y participación política de las mujeres: visiones desde Europa y América Latina, Valencia, Tirant lo Blanch, 2013, pp. 15-44.

96 Vid. J. Mansbridge, «Rethinking representation», American Political Science Review, vol. 97, núm. 4 (2003), pp. 523 y ss.

${ }_{97}$ Vid. M. SAWARD, «The Representative Claim», Contemporary Political Theory, vol. 5, núm. 3 (2006), pp. 297-318. 
común estas ideas e intereses mediante la deliberación como técnica, aceptando o rechazando las de los demás, llegan finalmente a acuerdos pactados que convierten $-\mathrm{o}$ intentan convertir- en políticas públicas. La idea de fondo, en este caso, es que la representación es un proceso cambiante y dinámico, no algo cerrado y unidireccional predicable entre unos (representantes) y otros (representados) ${ }^{98}$.

Los medios para alcanzar la democracia paritaria también mutan. Además de las cuotas - las cuales se revelan como mecanismos a veces eficaces, a veces menos- ${ }^{99}$ se adoptan medidas adicionales tales como la financiación directa al partido que mejora el índice de mujeres en el escaño, la lucha contra la violencia de género en el ámbito político (lato sensu, acoso sexual, acoso verbal, etc.), las estrategias gender-sensitive ${ }^{100}$ y el apoyo institucional, a veces realizando acciones simbólicas de cierto calado ${ }^{101}$.

Lo mismo sucede con los actores: no sólo importan los actores institucionales (partidos-Parlamento), sino también los extrainstitucionales (sociedad civil, ONGs, organismos relacionados con el feminismo institucional, etc). Los protagonistas son los llamados «actores críticos»; actores individuales y/o colectivos que plantean políticas públicas en la materia y que a menudo incentivan a otros actores a actuar en sentido similar ${ }^{102}$.

\section{CONCLUSIONES}

La democracia paritaria ha llegado para quedarse. Entendida como la distribución por igual del poder político entre mujeres y hombres, presen-

98 M. SAWARD, «Representation and Democracy: Revisions and Possibilities», Sociology Compass, vol. 2, núm. 3 (2008), pp. 1000-1113.

99 Vid. P. Biglino Campos, «Equal Representation in Spain: Lessons Learned from Balanced Electoral Lists», en Improving Electoral Practices: Case Studies and Practical Approaches, Stockholm, International Institute for Democracy and Electoral Assistance, 2015, pp. 203-224; A. Santana, X. Coller Porta y S. Aguilar, «Las parlamentarias regionales en España: masa crítica, experiencia parlamentaria e influencia política», Revista Española de Investigaciones Sociológicas, núm. 149 (2015), pp. 111-130, y A. EsPí-HERNÁNDEZ, «Presencia de la mujer y brecha de género en la política local española», Femeris, núm. 2-1 (2017), pp. 133-147.

100 Vid. L. WÄngnerud, The Principales of Gender-Sensitive Parliaments, New YorkLondon, Routledge, 2015, pp. 6 y ss.

${ }^{101}$ M. Lena KROOK, «Electoral Quotas and Beyond: Strategies to Promote Women in Politics», en DošEK et al. (eds.), Women, Politics, and Democracy in Latin America, New York, Palgrave Macmillan, pp. 18 y ss.

102 Vid. K. Celis, S. Childs J. Kantola y M. L. Krook, «Rethinking women's...», op. cit, p. 104. 
ta dos grandes fases/momentos que no sólo no se suceden cronológicamente entre sí, sino que en buena medida se desarrollan (se están desarrollando) en paralelo.

En primer lugar, la democracia paritaria se crea e impulsa en los años noventa del pasado siglo, llegando al convencimiento de que la discriminación de la mujer en política debe ser atacada (diagnóstico), distribuyendo el poder equitativamente (pronóstico). Para ello se implementan medidas tales como las cuotas electorales (acciones positivas más o menos refinadas), con porcentajes fijos de mujeres en las listas. La doctrina vuelca el concepto en las democracias representativas, observándose una serie de características teóricas y prácticas, además de unos factores — socioculturales y político-electorales- que influyen en su consecución.

Posteriormente, en la primera década del siglo XXI se abren las compuertas. Buena parte de las bases sobre las que se asienta la democracia paritaria se ven afectadas por nuevos planteamientos. En primer lugar, la propia noción y sus caracteres teóricos y prácticos. Ya no estamos ante medidas coyunturales que alcancen a mejorar la posición individual de las mujeres en política; ahora estamos ante algo estructural: la democracia es paritaria o no es democracia. Además, ya no estamos ante una representación guiada por los partidos y ejercida en las instituciones representativas. Ya no se cree que la representación descriptiva sea importante per se, ni que tampoco esté necesariamente unida a la representación sustantiva. Se discute ampliamente sobre los «intereses femeninos». Ya no hay intereses femeninos prefijados, se irán determinando conforme esos actores deliberen e interactúen en la esfera pública. También se expanden los sujetos representativos (no sólo partidos y Parlamento, también son protagonistas los «actores críticos»). Por último, junto a las cuotas electorales se impulsan medidas nuevas de fuerza nada desdeñable (la mejora de la financiación de los partidos que aumenten el número de representantes femeninas, las medidas gender-sensitive, la lucha contra la violencia que específicamente se ejerce contra la mujer en política, las acciones provenientes del feminismo institucional, etcétera).

Todo ello demuestra que la democracia paritaria es una noción viva, dinámica y transformadora, a la que tenemos que seguir prestando la atención que merece en el futuro. 